\title{
A Stability Indicating RP-HPLC for the Simultaneous Estimation of Hydrochlorothiazide, Amlodipine Besylate and Telemisartan in Bulk and Pharmaceutical Dosage Form
}

\author{
K. KALYANI ${ }^{1 *}$, V. ANURADHA ${ }^{2}$, S.VIDYADHARA ${ }^{3}$, \\ RLC.SASIDHAR ${ }^{3}$ and TNV.GANESH KUMAR ${ }^{3}$
'Department of Chemistry, R.V.R \& J.C College of Engineering, Guntur, A. P, India.
2Vignan's Nirula Institute of Technology and Science, Guntur, A.P., India.
${ }^{3}$ Chebrolu Hanumaiah Institute of Pharmaceutical Sciences, Guntur, A.P., India.
${ }^{*}$ Corresponding author E-mail: kk.chem445@gmail.com

http://dx.doi.org/10.13005/ojc/320340

(Received: March 11, 2016; Accepted: April 17, 2016)

\begin{abstract}
A stability indicating RP-HPLC method was developed for the simultaneous estimation of the anti hypertensive drugs Hydrochlorothiazide, Amlodipine Besylate and Telemisartan. These drugs were subjected to stress studies under different conditions as per ICH guidelines. The separations were carried out using $C_{18}$ reverse phase column (Agilent ODS UG 5 column, $250 \mathrm{~mm} \times 4.5 \mathrm{~mm}, 5 \mu \mathrm{m}$ ) employing Acetonitrile and Acetate buffer $(60: 40 \mathrm{v} / \mathrm{v})$ as mobile phase and $\mathrm{pH}$ adjusted to 5 at flow rate of $1 \mathrm{ml} / \mathrm{min}$ was used for separation, detected at $333 \mathrm{~nm}$. The drugs were exposed to acidic, alkaline, oxidative, thermal and photolytic conditions and the stressed samples were analyzed by the proposed method. Degradation studies showed that all the three drugs were degraded under oxidative, thermal and photolytic conditions, negligible degradation observed under acidic, alkaline conditions. Analytical validation parameters such as specificity, linearity, accuracy, precision, Ruggedness and Robustness were determined and relative standard deviation of all the parameters were found to be less than $2 \%$. Hence this method was found to be stable indicator that can be used for the routine analysis of these drugs in the bulk and combined tablet dosage form.
\end{abstract}

Keywords: Hydrochlorothiazide, Amlodipine Besylate, Telemisartan, RP-HPLC, Stress studies.

\section{INTRODUCTION}

Hydrochlorothiazide - $\mathrm{C}_{7} \mathrm{H}_{8} \mathrm{CIN}_{3} \mathrm{O}_{4} \mathrm{~S}_{2}$ (fig.1a) (HCT) chemically known as 6-chloro-3, 4-dihydro$2 \mathrm{H}-1,2$, 4-benzothiadiazine-7-sulphonamide, 1-dioxide.It is a first-line diuretic drug. Amlodipine besylate $-\mathrm{C}_{20} \mathrm{H}_{25} \mathrm{CIN}_{2} \mathrm{O}_{5}$ (fig.1b) (AMB) chemically known as (RS)-3-ethyl 5-methyl 2-[(2-aminoethoxy) methyl]-4-(2-chlorophenyl)-6-methyl-1, 4-dihydropyridine-3, 5-dicarboxylate mono benzene sulfonate. It is used to treat pressure and is a potent dihydro calcium channel blocker. Telmisartan 
$\mathrm{C}_{33} \mathrm{H}_{30} \mathrm{~N}_{4} \mathrm{O}_{2}$ (fig. 1c) (TEL) chemically 4'-[(1, 4'dimethyl-2'-propyl [2, 6'-bi-1H-benzimidazol] - 1'-yl) methyl]-[1, 1'-biphenyl]-2- carboxylic acid. It is also used to treat pressure and an angiotensin converting enzyme inhibitor and angiotensin - II type I receptor blocker ${ }^{1,3}$. Literature survey reveals that there were many analytical methods for all three drugs alone or in combination with other drugs including spectro scopic and chromatographic methods are reported ${ }^{4-10}$, but there is no method established for the stability indicating RP-HPLC under stress for this combination. The present work describes the development of stability indicating RP-HPLC method, which can quantify these components simultaneously from a combined dosage form. The present RP-HPLC method was validated ${ }^{11,12}$ and applied under stressed conditions according to International conference on harmonization $(\mathrm{ICH})$ guidelines. $\mathrm{ICH}$ has made the mandatory need of developing stability indicating assay methods for every drug candidates. There stability indicating assay methods helps in establishing the inherent stability of the drug which provides assurance on detection changes in identity, purity and potency of the product on exposure to various conditions.In the present study Hydrochlorothiazide, Amlodipine Besylate and Telemisartan is exposed to a variety of stress like acidic, basic, thermal, photolytic and oxidative stress conditions ${ }^{13}$. According to $\mathrm{ICH}$ guidelines the stress testing of the drug substances helps in identifying the likely degradation products, which in turn can help in establishing the degradation pathways and the intrinsic stability of the molecule. The aim of the present work was to develop stability indicating method for determination of all the three drugs in presence of its degradation products.

\section{EXPERIMENTAL}

\section{Instrumentation}

Analysis was performed with an Agilent ODS UG 5 column, $250 \mathrm{~mm} \times 4.5 \mathrm{~mm}$ with $\mathrm{C}_{18}$ column of injection capacity of $20 \mathrm{iL}$. The mobile phase was a $60: 40 \%(v / v)$ mixture of Acetonitrile: Acetate Buffer (50 mM, pH $5 \pm 0.1$, adjusted with orthophosphoric acid). The flow rate was $1.0 \mathrm{~mL} \mathrm{~min}^{\prime 1}$ and the run time was $15 \mathrm{~min}$. Before analysis both the mobile phase and sample solutions were degassed by the use of a sonicator (1.5LH Ultrasonic bath sonicator) and filtered through a $0.45 \mu$ membrane filter paper.
The identity of the compounds was established by comparing the retention times of compounds in the sample solution with those in standard solutions. Chromatography was performed in an ambient temperature maintained at $20 \pm 1^{\circ} \mathrm{C}$. The UV spectrum of HCT, AMB and TEL for selecting the working wavelength of detection was taken using a LAB INDIA double beam UV - Visible spectrophotometer with pair of $10 \mathrm{~mm}$ matched quartz cells.

\section{Reagent and chemicals}

Pharmaceutically pure sample of $\mathrm{HCT}, \mathrm{AMB}$ and TEL were obtained as a gift samples from Mylan laboratories. All solvents were of AR grade obtained from S.D. Fine chem. Limited, Mumbai. A combination of HCT (12.5 mg), AMB (5 mg), and TEL (40 mg) in tablet formulation was procured from Indian market TELVAS*-3D, Aristo pharmaceutical Pvt. Ltd, India.

\section{Preparation of Stock Solution of HCT, AMB and TEL}

About 50mg of HCT, AMB and TEL were accurately weighed and transferred in to $50 \mathrm{~mL}$ volumetric flasks separately. It was dissolved in methanol and the solution was made up to the volume with same solvent.

\section{Method of Validation}

The linearity of the prepared method was studied by injecting different concentrations of the HCT, AMB and TEL prepared in the mobile phase in the range of $20-100 \mu \mathrm{g} / \mathrm{mL}$ and the sample solutions were injected into HPLC system and peak areas were recorded. Precision of the method was demonstrated by interday and intraday variation studies. In the intraday studies analysis of $100 \%$ concentration of six replicate injections were performed in a day. In the interday variations studies the analysis of the drug was repeated on three consecutive days. Accuracy of the method was determined by recovery experiments. As known quantity of pure drug was added to the pre analysed sample and the contents were re analysed by the proposed method and percent of recovery was reported.

The limit of detection and limit of quantification were calculated from the slope of calibration curve. Robustness of the method was determined by carrying out the analysis by altering 
the conditions of mobile phase composition and flow rate and the effect on the area of peak of intercept and retention times were determined.

\section{Assay of marketed formulation}

The contents of twenty commercial tablets were weighed and their mean mass was determined. After grinding the tablets into a fine powder in a glass mortar, an accurately weighed quantity of the tablet powder equivalent to $40 \mathrm{mg}$ of TEL was quantitatively transferred into a $50 \mathrm{ml}$ volumetric flask. The contents were sonicated for $15 \mathrm{~min}$, to ensure the complete solubility of the drug. The solution was made up to the mark with the solvent and filtered through a 0.45 $\mu$ membrane filter paper. From the clear solution, further dilutions were made by diluting $1.0 \mathrm{~mL}$ into $10 \mathrm{~mL}$ with mobile phase; to obtain $100 \mu \mathrm{g} \mathrm{mL}^{-1}$ of TEL and $31.25 \mu \mathrm{g} \mathrm{mL}^{-1}$ of HCT and $12.5 \mu \mathrm{g} \mathrm{mL}^{-1}$ of AMB. Each sample solution was injected and the peak areas were measured for the determination of HCT, AMB and TEL in tablet formulation (table-2).

\section{Degradation Studies}

Forced degradation or stress test is undertaken to demonstrate specificity, when developing stability- indicating methods, particularly when little information is available about potential degradation products. These studies also provide information about the degradation pathways and degradation products that could form during storage. Forced degradation studies may help facilitate pharmaceutical development as well in areas such as formulation development manufacturing and packaging in which knowledge of chemical behaviour can be used improve a drug product ${ }^{14-16}$.

\section{Stress Degradation by Hydrolysis under Acidic Conditions}

For stability studies $2 \mathrm{~mL}$ of sample was taken from the HCT, AMB and TEL injection solution into a $100 \mathrm{~mL}$ volumetric flask and diluted up to the mark using mobile phase.

Acid hydrolysis of the drugs were carried out in presence of $1.5 \mathrm{~N} \mathrm{HCl}$. The drug solution was refluxed with $1.5 \mathrm{~N} \mathrm{HCl}$ for $2 \mathrm{hrs}$. After exposure for the required duration of time the stressed samples were sonicated and diluted to a concentration of $100 \mu \mathrm{gm} / \mathrm{mL}$ with mobile phase and then diluted to $10 \mu \mathrm{g} / \mathrm{mL}$ and was injected into the HPLC system after filtration.

Table 1: Results from study of linearity

\begin{tabular}{lccc}
\hline Parameters & HCT & AMB* & TEL $^{*}$ \\
\hline Detection wavelength & & $333 \mathrm{~nm}$ & \\
Beer's law limit $\left(\mu \mathrm{g} \mathrm{mL}^{-1}\right)$ & $20-100$ & $20-100$ & $20-100$ \\
Correlation Coefficient $(\mathrm{r})$ & 0.999 & 0.999 & 0.999 \\
Regression equation $(\mathrm{y}=\mathrm{mx}+\mathrm{c})$ & $\mathrm{Y}=14245 \mathrm{x}+40813$ & $\mathrm{Y}=10121 \mathrm{x}+15999$ & $\mathrm{Y}=11079 \mathrm{x}-25536$ \\
Slope & 14245 & 10121 & 11079 \\
Intercept $(\mathrm{a})$ & 40813 & 15999 & 25536 \\
LOD $\left(\mu \mathrm{g} \mathrm{mL}^{-1}\right)$ & 5.2 & 9.45 & 7.60 \\
LOQ $\left(\mu \mathrm{g} \mathrm{mL}^{-1}\right)$ & 17.16 & 31.18 & 25.08 \\
\hline
\end{tabular}

${ }^{*}$ Mean of six determinations

Table 2: Results from assay of tablet formulation

\begin{tabular}{ccccccccc}
\hline & $\begin{array}{c}\text { Amount Present } \\
\text { in (mg/tab) }\end{array}$ & TEL & HCZ & AMB & TEL & HCZ & AMB & TEL \\
HCZ & AMB & in (mg/tab) & Label Claim \\
\%w/w & \\
\hline 12.5 & 5 & 40 & 12.48 & 4.99 & 40.05 & 99.84 & 99.8 & 100.12 \\
\hline
\end{tabular}


Stress Degradation by Hydrolysis under Alkaline Conditions

The alkali hydrolysis of the drug was carried out in $0.1 \mathrm{~N} \mathrm{NaOH}$ and refluxing the solution for $8 \mathrm{hrs}$. After exposure the stressed samples were suitably

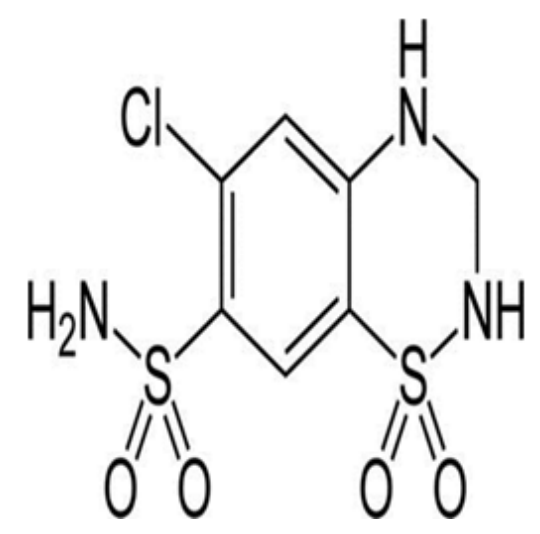

Fig.1(a): Hydrochlorothiazide<smiles>CCOC(=O)C1=C(COCCN)NC(C)=C(C(=O)OC)C1c1ccccc1Cl</smiles>

Fig. 1(b): Amlodipine Besylate

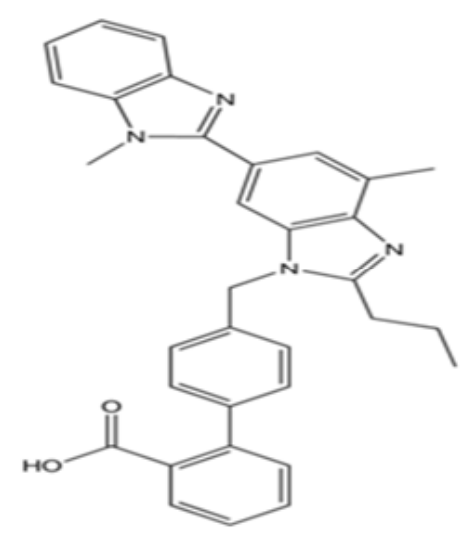

Fig. 1(c): Telmisartan diluted with mobile phase and then injected into HPLC system.

\section{Oxidative Stress}

The drug solution was prepared by dissolving $5 \mathrm{~mL}$ of $\mathrm{HCT}, \mathrm{AMB}$ and TEL solution in $10 \mathrm{~mL}$ of $1 \%$ hydrogen peroxide and refluxing the solution at $30^{\circ} \mathrm{C}$ for 24 hours. After exposure the samples were diluted, filtered and injected into the HPLC system.

\section{Thermal degradation}

HCT, AMB and TEL sample solutions was taken in a volumetric flask and kept in an oven maintained at $70^{\circ} \mathrm{C}$ temperature for 24 hours. Then the sample solution was dissolved and diluted in mobile phase. From this appropriate dilution was made mobile phase and injected in chromatographic system.

\section{Photolytic degradation}

$5 \mathrm{~mL}$ of HCT, AMB and TEL samples solution was exposed to ultraviolet lamp in a photostability chamber for $2 \mathrm{hrs}$. After exposure the stressed sample solution was suitably diluted with mobile phase and injected under stabilized chromatographic conditions.

\section{RESULTS AND DISCUSSION}

The present study was aimed to develop a simultaneous validated stability indicating RPHPLC method for the estimation of anti-hypertensive drugs Hydrochlorothiazide, Amlodipine besylate and Telemisartan. After several trails with different mobile phase compositions, a 60:40 ( $\mathrm{v} / \mathrm{v})$ mixture of Acetonitrile: Acetate Buffer $(50 \mathrm{mM}, \mathrm{pH} 5 \pm 0.1$, adjusted with orthophosphoric acid) was found to be good. This ratio was optimised as mobile phase for the simultaneous estimation of all the three drugs.

The data obtained from the calibration experiments when subjected to linear regression analysis showed a linear relationship in peak areas and concentration in the range of $20-100 \mu \mathrm{g} / \mathrm{mL}$ for each drug. The developed method was found to be precise as the \%RSD values for intra-day and interday precision studies were found to be less than $2 \%$. The recovery studies obtained at each added concentration indicates the accuracy of this method. 
The limit of detection of HCT, AMB and TELwas found to be $5.2,9.45,7.6 \mu \mathrm{g} / \mathrm{mL}$ and limit of quantification was $17.16,31.18,25.08 \mu \mathrm{g} / \mathrm{mL}$ respectively thus indicating the sensitivity of the method (table 1). While evaluating the robustness, the peak areas of all the three dugs were found to vary within $+0.009 \%$, whereas the retention was found to vary in the range of 2-8 $\mathrm{min}$. The method was robust as the peak areas and retention time were not significantly affected after varying the parameters like flow rate and wave length. The assay of commercial tablets was established with present chromatographic condition developed and it was found to be more accurate and reliable. The percentage label claim present in tablet formulation

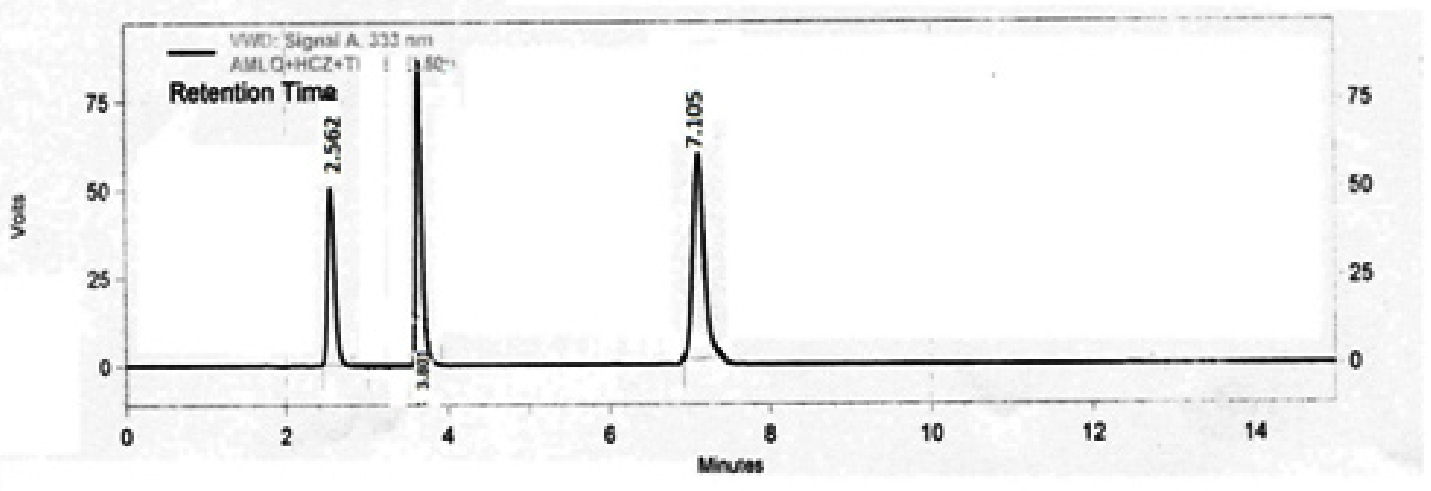

Fig. 2: Optimized chromatogram for HCT, AMB and TEL

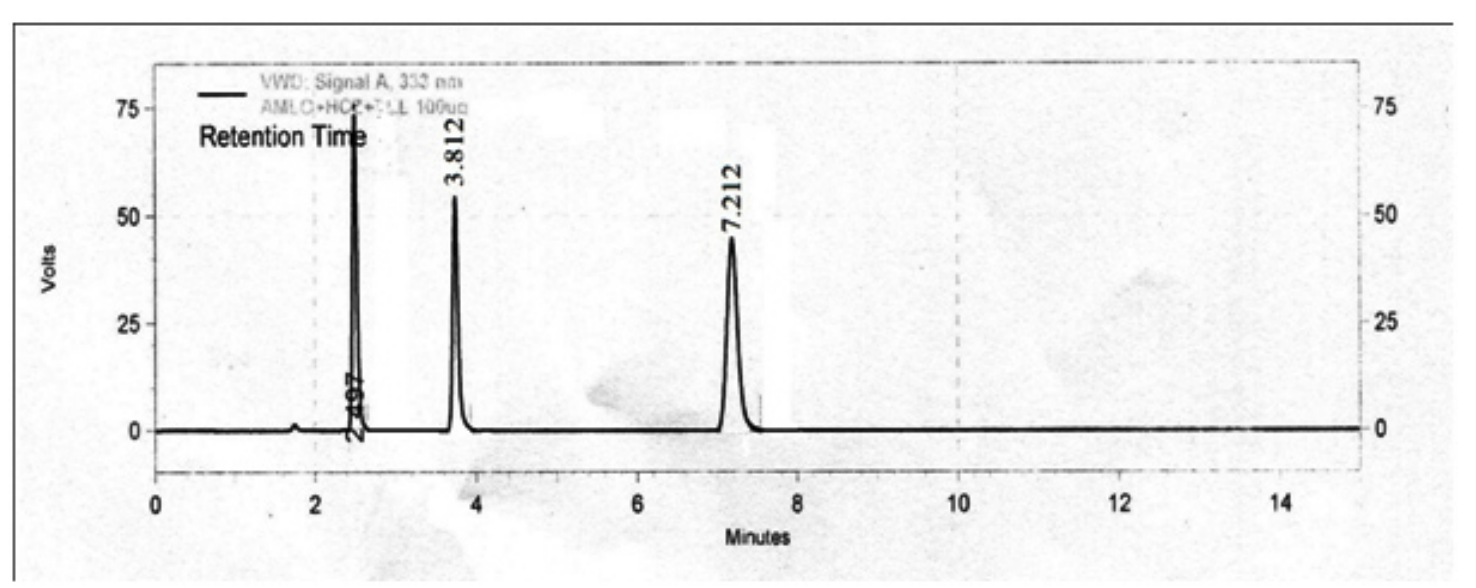

Fig. 3: Chromatogram for Assay of marketed formulation of HCT, AMB and TEL

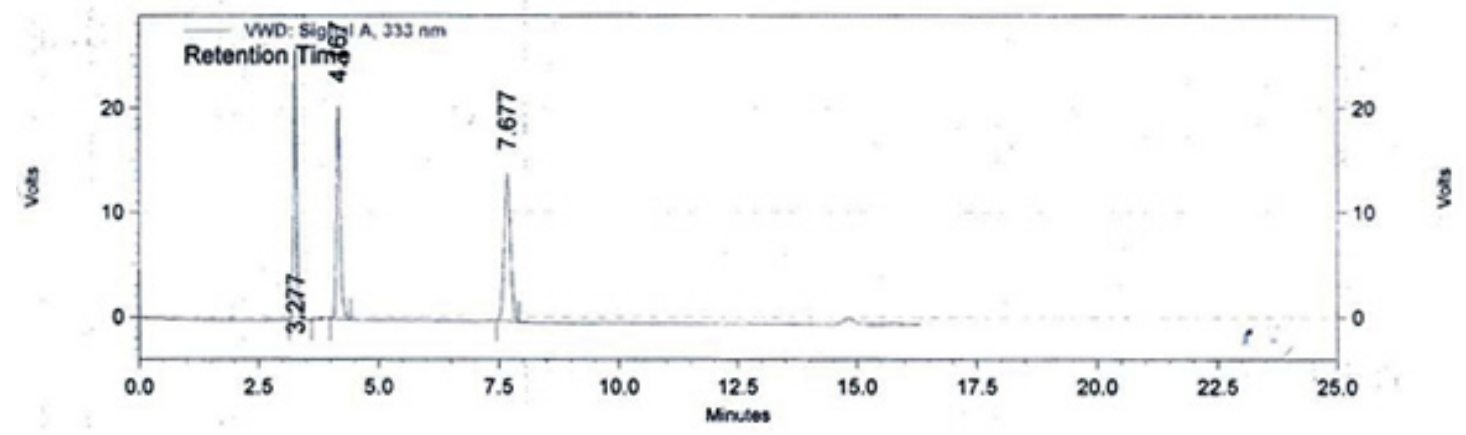

Fig. 4: Chromatogram for Acid Degradation 
TELVAS"-3D was found to be $99.84,99.8,100.12$ for HCT, AMB and TEL, respectively (Table 2). The chromatogram for the analysis of formulation is shown in Figure 3.

The drugs were exposed to acidic, base, oxidative, thermal and photolytic conditions and the stressed samples were analysed by the proposed method. Degradation studies showed that all the three drugs were degraded under oxidative, thermal and photolytic conditions. The drug peak areas decreased sufficiently with drastic change in the Rt values. Two new peaks were observed in chromatograms of acid and alkaline as when compared to the standard, which progressed without any change in Rt. The chromatograms of the stability studies were shown in the figures 4-7.

This present work on the three drugs Viz., $\mathrm{HCT}, \mathrm{AMB}$ and TEL shows maximum degradation in

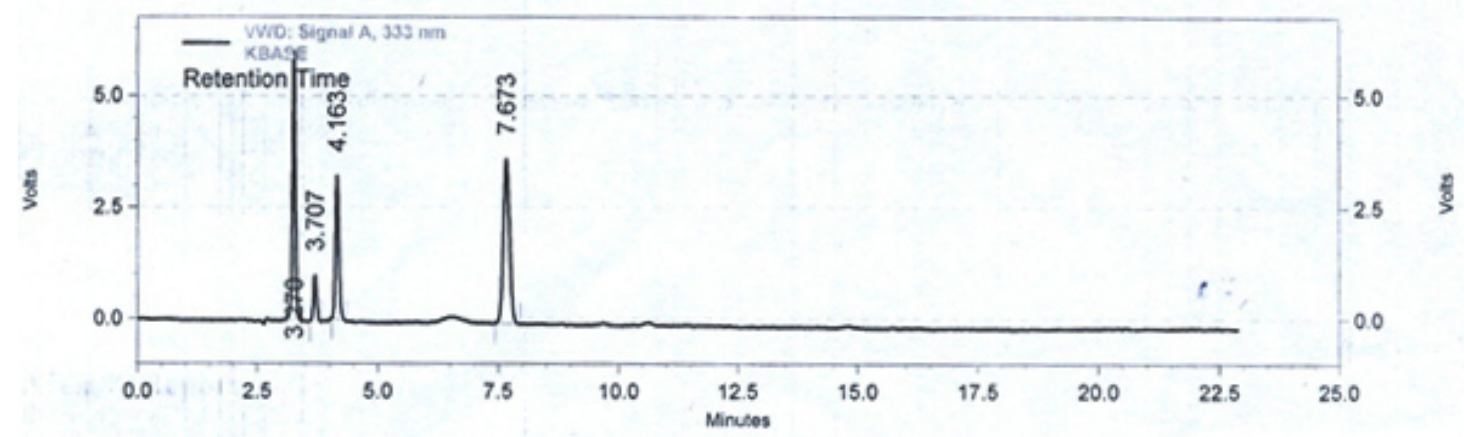

Fig. 5: Chromatogram for Base Degradation

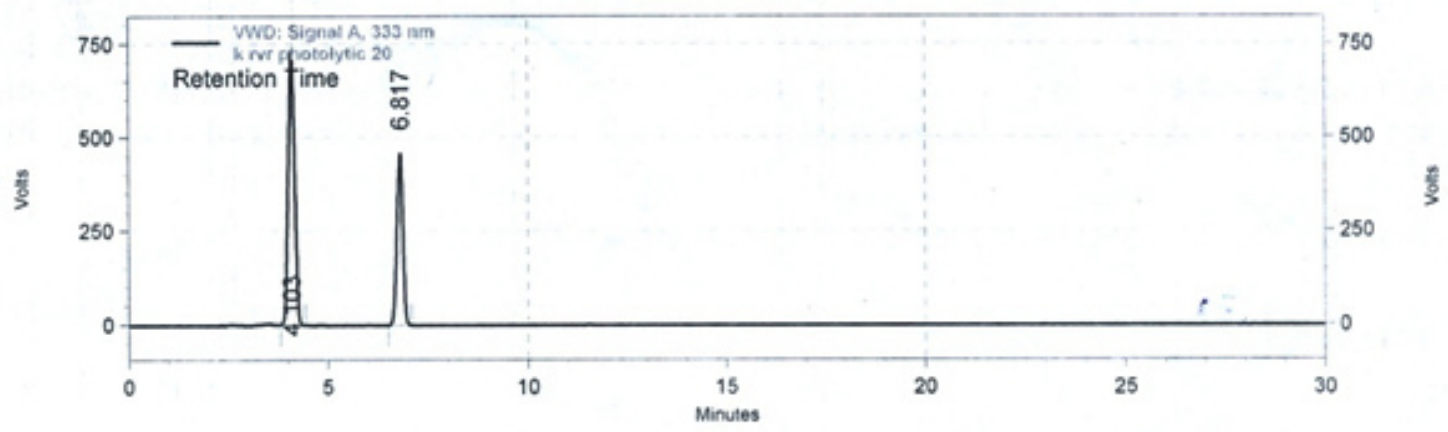

Fig. 6: Chromatogram for Photolytic Degradation

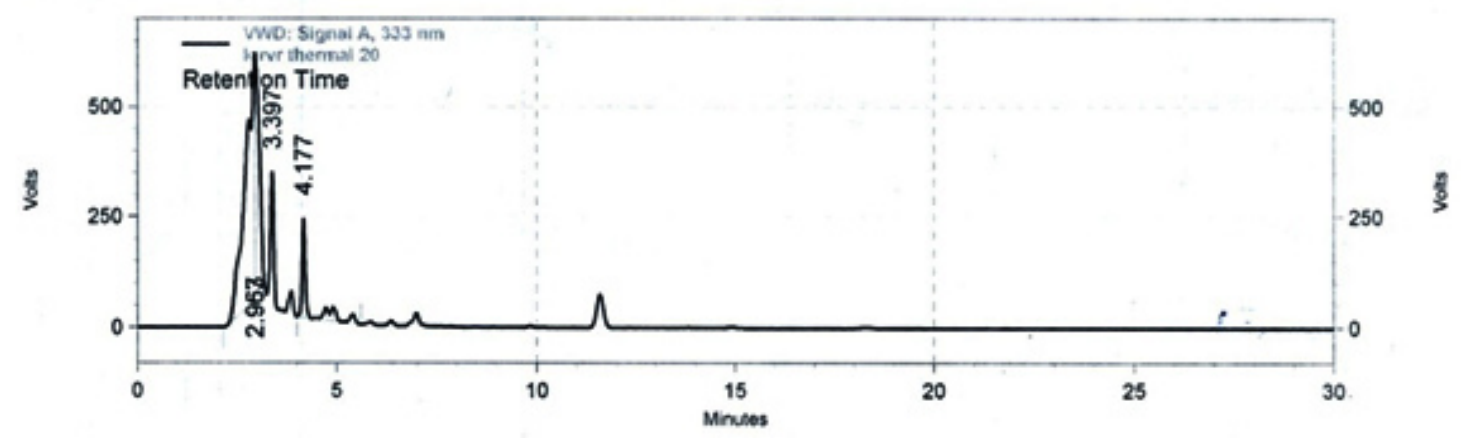

Fig. 7: Chromatogram for Thermal Degradation 
photolytic, thermal and oxidative conditions whereas relative stability was noticed when they were exposed to acidic and alkaline conditions. Thus the developed RP-HPLC method was found to be simple, rapid, sensitive, accurate, precise and specific for the simultaneous estimation of all the three drugs in bulk and pharmaceutical dosage forms and for routine analysis in stability studies of these drugs.

\section{CONCLUSION}

The HPLC method developed and validated allows a simple and fast quantitative determination of Hydrochlorothiazide, Amlodipine besylate and Telemisartan from its formulation. All the validation parameters were found to be within the limits according to the $\mathrm{ICH}$ guidelines. The proposed method was found to be specific for the drugs of interest irrespective of the excipients present and the method was found to be suitable for the routine analysis of the marketed formulation.

\section{ACKNOWLEDGEMENTS}

The authors are thankful to the Mylan Labs limited, Hyderabad for providing gift sample of Telmisartan, Amlodipine Besylate and Hydrochlorothiazide. The authors also extend their thanks to the management of R.V.R\&J.C College of engineering and Chebrolu Hanumaiah Institute of Pharmaceutical Sciences, Chowdavaram, Guntur for providing congenial facilities and support to carry out this research work.

\section{REFERENCES}

1. The Merck Index 14th Edition, Merck research laboratories 4581, 491, 9129.

2. Manish Maladkar, Vijay Kumar Verma.Open Journal of Internal Medicine, 2012, 2, 6771.

3. Indian Pharmacopeia. Amlodipine Besylate, Hydrochlorothiazide; Govt. of India, Ministry of Health and Family Welfare, Controller of Publication: New Delhi, 2007.

4. K. Muthu, R. Sankhla, S. Gupta, A. A. Smith, and R. Manavalan, Journal of Chemical Research,, 2010 , 12, 43-52.

5. Vijaya V, Vrushali T, Vrushali K, Dhole SN, Int. J. Chem. Res.2011, 2, 7 - 10.

6. Mallikarjuna Rao N, GowriSankar D, Int. J. Pharm. Pharm Sci. Res, 2011 , 1, 1 - 5.

7. Patel BA, Captain AD. Indo American Journal of Pharmaceutical Research, 2014,4(6), 3031-3038.

8. G. Saravanan, M. Padmaja, A. Lakshmi Gowthami, Journal of Chemical and Pharmaceutical Sciences, 2014, 7(3), 224228.
9. ShivajiJadhav, MeghaRai, Kawde.P.B and Mazahar Farooqui ,Der Pharmacia Sinica, 2015, 6(4),13-18.

10. RLC Sasidhar, S.Vidyadhara, B.Deepti, K.Tejaswi and J.Suhasini, Oriental Journal of Chemistry, 2014, 30 (4), 1815-1822.

11. ICHQ2A; Guidelines on validation of analytical procedure; Definitions and terminology, Federal Register, 60, 11260 (1995).

12. $\mathrm{ICH}$ Q2B; Guidelines on validation of analytical procedure; Methodology, Federal Register, 60, 27464 (1996).

13. $\mathrm{ICH}$ harmonized tripartite guideline, stability testing of new drug substances and products, Q1A (R2), 115 (2003).

14. Kishore kumar.H, S.Phani Kumar Reddy. International Research Journal of Pharmacy, 2013, 4(5), 78-84.

15. Reddy,G.S; Reddy,S.L.N.P; Reddy,L.S. Orient.j.chem.,2013,29(4),1371-1380.

16. Reddy,L.S; Reddy,S.L.N.P; Reddy,G.S. Orient.j.chem.,2014,30(3),1243-1251 